\title{
Research on the Development of Modern Environment Art Pattern under the Perspectives of Green City and Environmental Protection
}

\author{
Kang Zhou \\ Art Institute of Jiujiang University, \\ JiuJiang,Jiangxi, 332005 China
}

\begin{abstract}
In this paper, we conduct research on the development of modern environment art pattern under the perspectives of green city and environmental protection. Environmental art and practical function refers to the practical use of it, fitness for a particular purpose or use value, is also the most concern of the basic user. Practical function is the most basic level in the environmental art design, environmental art and practical function and the traditional social system, history, ethnic customs, science, culture, economic development level, and there is a close relationship between geographical environment and so on. Environmental art including landscape and soft landscape two kinds big. Soft landscape plant configuration and plant layout as the main content, hard landscape sketch facilities including floor, ground shop, and environment and therefore, environmental art and practical function mainly reflects in the hard landscape design, the environment landscape facilities to provide practical purpose or use value. Our research proposes the related new idea that is meaningful.
\end{abstract}

Keywords- Environment Art, Perspectives, Green City, Environmental Protection, Modern.

\section{Introduction}

At present, the construction of the green city is increasingly becoming the mainstream direction of the future urban development in our country, especially need to create green city formed in the practical work of strong maneuverability, can guide the practice of theoretical support and experience for the reference. Based on the research on green cities at home and abroad on the basis of related literature review on the concept and the connotation of the green city, city green transformation of developed countries and summarizes practical experience, thought that building a green city in our country, the development of urban green for reference [1-3].

Green ecological city is the space layout, infrastructure, construction, transportation, industry, etc., according to the requirements of resource saving environmental friendly planning, construction and operation of city development zone, functional area, new district, etc. In order to achieve economic and environmental benefits of the green ecological city construction is the foundation, the operation is more critical. Small scale as a green ecological city is not enough to reflect the economic and social benefits, but the area is too large, involving the general administrative jurisdiction conflict, make the construction and management coordination difficult. So, the size of the green ecological city should be within the jurisdiction of a single administrative region under it, otherwise poor maneuverability. Promote the work of green ecological city at present or in the planning and design stage as the center of gravity but should provide the good foundation for the long-term operations of the green ecological city. Green ecological city traffic, electric power, energy, communications, water, garbage disposal is a subsystem of the urban system, such as its system technology inevitably restricted by the superior overall city. But all kinds of green ecological city system can higher technology level [4].

Development is the pursuit of the eternal theme of human society as human history is human social interaction with nature and common evolution, the coordinated development 
of the history. In social progress, human beings constantly summarize the experience of the pros and cons, insisted on under the condition of invariable total target, selection, constantly adjust their own development model. There is no doubt that have astonished the world, the trend of economic development in our country in the new and high technology in many fields, including environmental art design, is also achieved new breakthroughs, constantly formed an all-round way influence human survival and development of the human environment. The change of ideas is not without foundation, still needs a series of system to protect. One of the most critical is the art of the general environment decision-making system and the establishment and perfection of the design system. Decision system problems should belong to a more macro government behavior, environment art of the concept of the scientific development from the concept of the right decisions, it is difficult for us to step in, only comments and Suggestions. As soon as possible, adjust and improve the old system of evaluation concept and design, is to set up scientific view of development of a long-term primary work environment art. Obviously, establish a scientific, decision-making mechanism and evaluation mechanism which accords with the situation of China's environmental art design system can improve the basic premise.

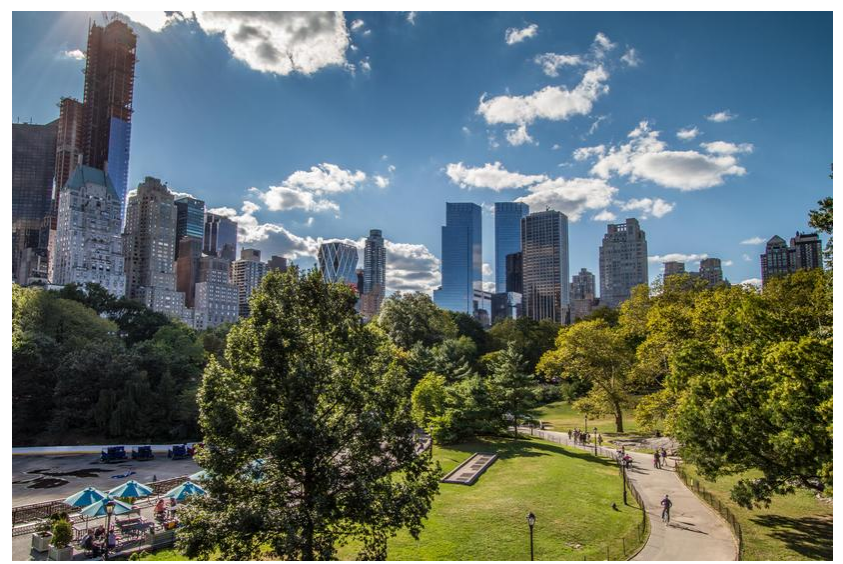

Figure 1. The Ideal Model of the Green City Concepts
In this paper, we conduct research on the development of modern environment art pattern under the perspectives of green city and environmental protection. Between the environmental art design and the ecological concept is the dialectical, the development of the relationship. People's environmental design concept has a decisive influence to the characteristics of the environment design, and excellent environmental art design can guide people's concept of basic environmental design change to improve people's aesthetic standard, thus achieve basic edify sentiment, and beautify the life, enhance people's consciousness of environmental protection and sustainable development.

\section{Our Proposed Perspective and Methodology}

The Principles and Concepts of the Green City. Green city is not only a kind of brand-new values and concept of city development, is also a kind of "green city", the consciousness and concept to guide urban related benefit main body respecting nature, and the nature in harmony, but so far, the existing works or focused on qualitative analysis, or just some aspects of artistic description has not yet have a recognized in the world in the true sense of green city as also is not a generally accepted definition.

From the perspective of the constituent elements of green residential environment design, it mainly by the survival environment of urban population and its two parts, the survival environment including natural environment, biological environment, physical environment and social environment in four aspects of content. (1) In green living environment, the diversity is endowed with rich social meaning, it not only includes the diversity of species, also includes the macro function and the diversity of basic human activities, etc. It can through a variety of the basic functional unit of the human settlements of niche overlap, in narrow space to create a diversity of residential space environment. (2) Convenience of green 
residential environment is mainly in the residential environment of internal and external transportation, public facilities and services, and so on. From the point of residential traffic system inside, not only to meet the needs of the settlements of residents as also must provide convenience for the internal traffic of the residential house. (3) Green residential environment should strive to build a sunny, fresh air, no pollution and noise environment space, and has the broad green space and outdoor activity space that has a perfect identification system and good landscape effect, and so on. (4) As an important part of city in the overall environment of living environment and the development of the artificial environment and natural environment, must consider the links with the overall environment, such as the size of the residential environment, content, function, structure and layout, and the density of residential buildings, such as height, modelling, color, material and style should be incorporated into the overall environment in the relationship to think, in addition to people, the society and nature should be regarded as a complete harmonious system combine the design and green ecological system stability with the use of natural law to carry on the design [4-6].

Urbanization is a kind of green in order to improve the production quality of life as the core of the connotative development process. Its basic characteristics are the use of primary resources and energy efficiency can be significantly increased with the improvement of the urbanization rate, and properly solve the urban development in the course of development of the high consumption, high emission and high pollution and other issues. City advanced productivity and advanced culture of radiation and diffusion effect was improved continuously, production factors and the free flow of system barriers to free migration, configuration of the production factors mainly through the market mechanism and become more efficient. Economic development must get rid of the industrial economic thinking and towards a new multidimensional strategy and industry development need to move to tilt of the green cluster effect and multivariate innovation and rely on, in the knowledge production, and basic service support, financial innovation, science and the technology revolution and cultural creation, and other fields to seek visionary growth. Should pay attention to the spread of the core public service function, to improve the important role of the free enterprise and small micro enterprise to make the city green prosperity has a wide range of energy saving and sustainable power.

The Environmental Protection Perspective. At present, the wisdom cities gradually become a worldwide topic, the future will gradually appear intelligent, information, ecology, energy saving, low carbon, safety features. Therefore, it is necessary to cognitive wisdom from the angle of ecological city, will optimize the concept of wisdom city that construct a fused into the concept of the ecological wisdom city new pattern. By means of various techniques of information age, the use of the Internet of things, cloud computing and other intelligent methods, the city of the physical, social and commercial infrastructure, information fully connected and truly universal service. The concept of beginning from the date of proposed caused extensive concern of the world and the ecological city basically has the following several characteristics [7].

- Regional. Ecological city based on concept of regional balance, committed to the integration of urban and rural, the coexistence of different between the city only through the coordination and balance, to achieve balance coordinate the establishment of ecological city.

- Relationship coordination. The general original vision of the ecological city is to realize the harmonious development of man and nature, so we must pay attention to urban and rural areas as a whole, resource utilization and renewal, the 
environmental stresses in harmony with its bearing capacity.

- The structure is reasonable. Ecological city is to realize the long-term development, must first of all based on a reasonable structure, traffic facilities, land use, the green space system and the public facilities should be included.

- High efficiency. Focus on improve the utilization rate of resources, reasonable plan as a whole resources, optimize configuration, multi-level use of all kinds of the materials and energy. In logistics and orderly flow, convenient and the quick waste recovery and recycling, through the symbiotic relationship coordination between industries.

From the perspective of ecological development, intelligent city should be on the basis of the city information as the primary driving force, to join the technology of the ecological factors, so as to help achieve the urban ecological transformation and general efficient operation. Again by means of the development mode of the innovation, comprehensive introduction of system engineering, information technology, ecological economics knowledge to improve urban management and decision-making, such as basic production and consumption mode, further excavate the potential of urban ecological resources, and ultimately helps to make the city to pay equal attention to ecology and informatization and the economic booming new modern of the city status [8].

For urban development under the perspective of ecological wisdom, on the basis of the information is considered more urban ecological environment problems. Refers to the optimization of basic urban ecological environment, and urban life quality to improve the development direction of the relevant industry combined with the resources comprehensive utilization of adjustment, the adjustment for the traditional industry, the emerging technology industry and environmental protection industry has new requirements. From the point of view of the traditional industry, this kind of ecology refers to people in daily production and consumption into the concept of the environmental protection pay attention to the circulation and comprehensive utilization of the resources, reduce noise, rubbish, dirty air, such as industrial waste water influence on city environment, mainly through the use of the ecological design materials, develop and expand resources industry and primary pollution bigger industries alternative industries, increase the comprehensive utilization of waste and recycling and implement ecological compensation system and other ways shown in the following figure.

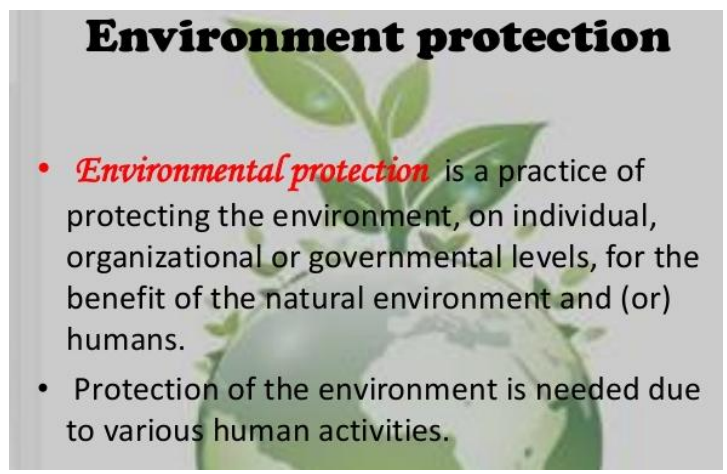

Figure 2. The Primary Definition of the Environemntal Protection

The Modern Environment Art Pattern. Environmental art design is a cover a wide range of the basic discipline, it involves architecture, planning, materials science, technology, ecology, aesthetics, morphological disciplines, both has general characteristics of the visual arts, and science, technology, engineering characteristics. It is "organization for all kinds of the natural and artificial environment factors as make it accord with the people's life and psychological needs, and produce the aesthetic feelings an emerging discipline, is the concrete form of the environmental aesthetics." Substances are contained in the environmental art design environment and the physical environment and physical environment has two aspects of natural 
environment and artificial environment that fused artificial building and natural environment, to achieve a harmonious unity of state, thus to promote the further development of the city with residents of rich humanistic connotation.

Environmental art design of the ecological philosophy can be summarized as: the basic function to ensure good quality of life and all the people under the premise of normal operation, design scientific and reasonable space environment, to ensure the virtuous cycle of ecological system and the rational allocation of resources, reduce the consumption of the material and energy, to achieve the harmonious coexistence of man and nature that could be summarized as the following aspects.

- The principle of respecting nature. Natural law, has its own evolution and update again at the same time has a strong self-sustaining and resilience, environmental art design should make full use of the natural to the function of ecological recovery. Respect the natural development process, enhance the field of the self-regulation, and realize its sustainable development is an important principle in ecology in environmental art design concept.

- The principle of art to participate in. Environment is an integrated whole, the design is an art. Designer shall be based on the ideas of general modern art to understand the design of the environment, and to create that contains artistic aesthetic feeling, and meet the social function of modern new environment [9].

- The principle of minimal intervention promote biggest. Environmental art design is always in a certain field, human activities on the natural environment are bound to produce interference. Environmental art design is to minimize the disturbance of the venue, and efforts to promote through the design of the natural ecosystem of material utilization and energy circulation, the natural process and pattern of original ecological maintenance ground to enhance biodiversity.

\section{Conclusion}

In this paper, we conduct research on the development of modern environment art pattern under the perspectives of green city and environmental protection. Environmental art is made up of a variety of art organic whole, is a throughout the environmental art design has always been the general concept of the art, not the physical environment, such as architecture, interior space and outdoor space design. Environmental art broad in object, space, time, determines it has the characteristics of many other art categories do not have, it is different from a single art, is also not pure architectural art, garden art, sculpture, painting and so on synthesis of mechanical, and the environmental interdependence cycle characteristics, limited and restricted by the environment. Our research combines the general concept of the green city and environmental protection to propose the development of modern environment art pattern that is novel and meaningful with special significance.

\section{References}

[1] Freitas, S., et al. "Modelling solar potential in the urban environment: State-of-the-art review." Renewable and Sustainable Energy Reviews 41 (2015): 915-931.

[2] Liu, Wei, et al. "State-of-the-art methods for inverse design of an enclosed environment." Building and Environment 91 (2015): 91-100.

[3] Ghalib, Md, Mohd Feham, and Gairuzazmi Mat Ghani. "Innovative teaching and learning environment system (iTa'LEem): implementing a state-of-art platform for 
managing E-learning." Bulletin MEIPTA 2 (2014): 17-19.

[4] Pawela, Łukasz, and Zbigniew Puchała. "Quantum control robust with respect to coupling with an external environment." Quantum Information Processing 14.2 (2015): 437-446.

[5] Juzefovič, Agnieška. "Landscape as Communication: Reflection on Surrounding Environment in Chinese Aesthetics." Limes: Borderland Studies 6.1 (2013): 32-45.

[6] Ehmann, Falk, et al. "Gatekeepers and enablers: how drug regulators respond to a challenging and changing environment by moving toward a proactive attitude." Clinical Pharmacology \& Therapeutics 93.5 (2013): 425-432.
[7] Trocan, Laura Magdalena. "The impact of the activities developed in the international zone of submarine territories upon the marine environment and measures undertaken for protection of this environment." 13-th International Multidisciplinary Scientific Geoconference SGEM (2013).

[8] Gao, Ruipeng, Fan Ye, and Tao Wang. "Smartphone indoor localization by photo-taking of the environment." ICC. 2014.

[9] Lin, Angela Yu-Chen, et al. "Occurrence of perfluorinated compounds in the aquatic environment as found in science park effluent, river water, rainwater, sediments, and biotissues." Environmental monitoring and assessment 186.5 (2014): 3265-3275. 